Vol 11, Issue 4, 2018

\title{
PULMONARY TUBERCULOSIS - A PROSPECTIVE ANALYSIS OF HEMATOLOGICAL CHANGES
}

\author{
SONTI SULOCHANA*, SUBHASHINI V, CHITRA SRINIVASAN \\ Department of Pathology, Saveetha Medical College and Hospital, Chennai, Tamil Nadu, India. \\ Email: Sulochanamaster@gmail.com
}

Received: 23 November 2017, Revised and Accepted: 30 December 2017

\section{ABSTRACT}

Objective: This study was a prospective analysis of hematological changes in pulmonary tuberculosis (TB). The objectives of this study are (1) to study the changes in different parameters of hemogram in association of sputum-positive pulmonary TB, (2) to evaluate the disease severity and patient infectivity, (3) to determine the most common type and severity of anemia in pulmonary TB patients, and (4) to count platelets in pulmonary TB patients. TB is an important communicable disease in the world and is a major public health problem in India. Hematogical abnormalities associated with TB have been completely investigated in the literature though it is a common condition in India.

Methods: A total of 150 patients of acid-fast bacilli-positive cases were included, and disseminated TB, childhood TB, and patients receiving anti-TB drugs were excluded from this study.

Results: Among the 150 patients, anemia was observed in 116 cases, normocytic normchromic and microcytic hypochromic picture, leukocytosis in 68 patients, thrombocytosis in 50 patients, thrombocytopenia in 5 patients, and ESR levels were elevated in more than $82 \%$ of patients.

Conclusion: A complete hemogram has been demonstrated in patients with acid-fast bacilli-positive cases in the present study. Since there was a paucity of literature in the hematological changes associated with TB, this study aimed at reinforcing the fact that they can be valuable tools in monitoring pulmonary TB.

Keywords: Tuberculosis, AFB stain, Anemia, Leukocytosis, Thrombocytosis, ESR.

(C) 2018 The Authors. Published by Innovare Academic Sciences Pvt Ltd. This is an open access article under the CC BY license (http://creativecommons. org/licenses/by/4. 0/) DOI: http://dx.doi.org/10.22159/ajpcr.2018.v11i4.23177

\section{INTRODUCTION}

Tuberculosis (TB) is a chronic infectious disease caused by mycobacterium TB. In developing countries, pulmonary TB is a common disease [1]. TB is a major global health problem. The disease can infect 10-15 persons per year and an annual risk of $0.5-2 \%$ in high burden countries [2,3]. One-third of world population and nearly 3 million people die annually from pulmonary TB [4].

Mycobacterium TB is a facultative intracellular parasite, i.e., readily ingested by phagocytes and is resistant to intracellular killing [5]. The Indian TB bacillus is less virulent than the European bacillus. In recent years, a number of atypical mycobacteria have been isolated from man. These are classified into four groups: (1) Photochromogens (e.g. $M$. kansasii), (2) scotochromogens (Mycobacterium scrofulaceum), (3) nonphotochromogens(M.intracellulare),and(4)rapidgrowers(Mycobacterium fortuitum), all these are saphrophytic.

The most common source of infection is mainly diseased persons form droplets in the air during speaking, coughing, and sneezing [6] or the human cases with sputum positive for TB bacilli and who has either received no treatment or has not been treated fully. The bovine source of infection is usually infected milk. Patients are infective as long as they remain untreated. Effective antimicrobial treatment reduces infectivity by $90 \%$ within $48 \mathrm{~h}$ [7].

TB affects all ages. In India, the infection rate is $20 \%$ at the age of $15-24$ years age and $2 \%$ in $0-14$ years of age group. In developed country, the disease is more common in older age group and more prevalent in males than females. It is not a hereditary disease, but twin studies [8] indicate that inherited susceptibility is an important risk factor.
TB is a social disease with medical aspects. The non-medical or social factors include poor quality of life, poor housing and overcrowding, population explosion, malnutrition, smoking, alcohol abuse, lack of education, large families, early marriages, and lack of awareness of causes of illness. All these factors are interrelated and contribute to the occurrence and spread of TB. HIV is the most potent risk factor for progression of TB infection to disease $[9,10]$.

The tests used for the diagnosis of TB was by sputum examination for acid-fast bacilli, culture, TB skin test, chest X-ray and computed tomography (CT) scan, nucleic-acid amplification, and polymerase chain reaction (PCR) tests. There are studies in TB patients with hematological changes because it is a bacterial infection which secretes some substances and affects some hematological parameters in active pulmonary TB anemia, and iron deficiency erythropoiesis was observed. There was a close correlation between acid-fast bacilli in sputum and abnormal hematological value.

\section{Rationale}

The aim of the study is to analyze the hematological changes in pulmonary TB patients. This study can be helped to reduce the rate of morbidity and mortality and to avoid complications of the disease. The study may be useful as indicators of disease progression.

Here, we studied a prospective analysis of hematological changes in sputum-positive TB patients from January 2017 to August 2017.

\section{METHODS}

A prospective analysis of hematological changes in sputum-positive TB patients was analyzed from January 2017 to August 2017. The age group was adult male and female patients, and an exclusion criterion 
was children's, TB patients on treatment, HIV, and other associated systemic diseases.

\section{Sputum examination}

Sputum smear examination by direct microscopy considered as the method of choice, and it is number one case finding method all over the world, due to reliability, cheapness, and ease. The increasing number of new PTB infection cases every year is due to diseased patients excreting TB bacilli in their sputum.

Pulmonary TB was defined as being sputum smear positive in at least two microscopic examination, or sputum smear positive in one microscopic examination plus culture or abnormal chest X-ray shows TB. Smear negative tuberculosis is three negative smears but tuberculosis suugestive symptoms and abnormal chest X-ray shows TB or culture positive [11]

Sputum samples were collected from patients and stained by the ZiehlNeelsen method and examined by pathologist.

\section{Collection of sputum sample}

Day 1 sample is on the spot sample under supervision when presenting to the health facility. Give the patient a sputum container to take home for an early morning sample.

Day 2 sample patient brings an early sample.

If the patient is coming from the long distance or any default to give a second sample, two spot specimens are collected with a gap of $1 \mathrm{~h} \mathrm{[12].}$

\section{Procedure for Ziehl-Neelsen acid-fast stain}

Fix the smear on the slide by passing the slide with the smear up about 3 times slowly through a flame. It can also do by covering the smear with alcohol and letting this evaporate.

1. Cover with carbol fuchsine, steam gently for 5 min over a direct flame (or 20 min over a water bath).

2. Wash with deionized water

3. Decolorize in 3\% acid alcohol (95\% ethanol and $3 \%$ hydrochloric acid) until only a faint pink color remains.

4. Wash with water.

5. Counterstain for 1 min with Loffler's methylene blue.

6. Wash with deionized water and let it dry.

\section{Slide reporting [13]}

It is important to record the number of bacilli seen on each smear which gives patient infectivity and disease severity. The following table presents the standard method of reporting using $\times 1000$ magnification.

\begin{tabular}{lll}
\hline $\begin{array}{l}\text { Number of } \\
\text { bacilli }\end{array}$ & $\begin{array}{l}\text { Microscopic examination of } \\
\text { sputum for AFB; Number of bacilli } \\
\text { counted under oil immersion }\end{array}$ & Results \\
\hline No & AFB per 100 oil immersion fields & 0 \\
$1-9$ & AFB per 100 oil immersion fields & Scanty \\
$10-99$ & AFB per 100 oil immersion fields & $+(1+)$ \\
$1-10$ & AFB per oil immersion fields & $++(2+)$ \\
$>10$ & AFB per oil immersion fields & $+++(3+)$ \\
\hline
\end{tabular}

It is advised that the smear examined by one person should not exceed 20 per day as visual fatigue leads to deterioration of reading quality [14].

\section{Blood sample analysis}

Anticoagulated venous blood $2.5 \mathrm{ml}$ was obtained from patients and analyzed by Sysmex XN 1000i six-pasrt instrument in central clinical laboratory. Principally, it is based on the impedance detection method for counting and sizing recognition of the leukocytes, erythrocytes, and platelets using three hydraulic systems for white blood cells (WBC), red blood cells (RBC), and hemoglobin and displays the results on the liquid crystal displayer with histogram and printed out the results in paper.
The reagents and materials used in Sysmex are cell pack and stromatolyser diluents and lysing reagents. The function of Detergent and cell cleaner is for cleaning solution to remove lysing reagents, cellular residuals, and blood proteins remaining in the hydraulics of Sysmex automated hematology analyzers.

The parameters analyzed by this are hemoglobin $(\mathrm{Hb} \mathrm{g} / \mathrm{dl}), \mathrm{RBC}$ count, RBC indices (MCV, MCH, MCHC), PCV, total count (WBC count), differential count (neutrophils, lymphocytes, monocytes, eosinophils, and basophils), and also platelets.

This study was approved by IRB and Ethical committee.

\section{RESULTS}

One hundred and fifty patients who were sputum positive for AFB were included in the study. There were 116 males and 34 females with mean age of 50 years in males and 37 years in female.

The mean Hb levels in males were $11.13 \mathrm{~g} / \mathrm{dl}$ and in females $9.8 \mathrm{~g} / \mathrm{dl}$. The mean hematocrit was $34.6 \%$ in males and $31.4 \%$ in females.

The definition of anemia used in this study was $\mathrm{Hb}$ concentration $<13.5 \mathrm{~g} / \mathrm{dl}$ in males and $12.5 \mathrm{~g} / \mathrm{dl}$ in females.

Anemia was present in 116 patients $(77.3 \%)$, of which males were 88 and females were 28. Prevalence of anemia in TB patients with sputum smear showing $1+$ is $74 \%(40 / 54)$. Prevalence of anemia in TB patients with sputum smear showing $2+$ is $77 \%(27 / 35)$. Prevalence of anemia in TB patients with sputum smear showing $3+$ is $88 \%$ (24/27). MCV was decreased in 36 patients and MCHC was decreased in 21 patients (Table 1).

Leukocytosis was present in 68 patients (45.3\%), of which males were 49 and females were 19. Prevalence of leukocytosis in TB patients with sputum smear showing $1+$ is $42 \%$ (23/54). Prevalence of leukocytosis in TB patients with sputum smear showing $2+$ is $57 \%$ (20/35). Prevalence of leukocytosis in TB patients with sputum smear showing $3+$ is 55\% (15/27). Neutrophilia was observed in 90 patients, of which males were 73 and females were 17. Eosinophilia was observed in 15 patients, of which males were 12 and females were 3 . Lymphocytopenia was observed in 70 patients, of which males were 60 and females were 10 .

Thrombocytosis was present in 50 patients $(33.3 \%)$, of which males were 38 and females were 12. Prevalence of thrombocytosis in TB patients with sputum smear showing $1+$ is $29 \%$ (16/54). Prevalence of thrombocytosis in TB patients with sputum smear showing $2+$ is $31 \%(11 / 35)$. Prevalence of thrombocytosis in TB patients with

\section{Table 1: Hematological abnormalities in total TB cases}

\begin{tabular}{ll}
\hline Total & Out of $\mathbf{1 5 0}$ cases (\%) \\
\hline Anemia & $116(77.3)$ \\
Leukocytosis & $68(45.3)$ \\
Neutrophilia & $90(60)$ \\
Lymphopenia & $107(71.3)$ \\
Esonophenia & $53(35.3)$ \\
Esonophilia & $15(10)$ \\
Monocytosis & $7(4.6)$ \\
Monocytopenia & $13(8.6)$ \\
Basophilia & $1(0.6)$ \\
RBC (decreased) & $117(78)$ \\
MCV (Decreased) & $36(24)$ \\
MCV (Increased) & $2(1.3)$ \\
MCH (decreased) & 4 \\
MCH (increased) & 80 \\
MCHC (decreased) & $21(14)$ \\
MCHC (increased) & $4(2.6)$ \\
Thrombocytopenia & $5(3.3)$ \\
Thrombocytosis & $50(33.3)$ \\
\hline
\end{tabular}


sputum smear showing $3+$ is $51 \%(14 / 27)$. Thrombocytopenia was seen in 5 cases, of which 4 in males and 1 in female (Table 1 ).

ESR was increased in 75 patients of 91 cases, males were 57 (out 72 cases) and females were 18 (out of 19 cases).

\section{DISCUSSION}

The most common communicable disease in the world is TB and is a major public health problem in India. In 1993, the WHO declared that TB is a global emergency. In 2014, TB was the main cause of death due to infectious diseases worldwide. Among the 22 countries, $80 \%$ of cases are noticed in Brazil and the state of Rio de Janeiro has the highest mortality and the second highest incidence in 2014 [15].

The prevalence of TB in India in 2015 is 2.5 million [16]. It is estimated that about $40 \%$ of the Indian population is infected with TB bacteria. The patients who have cavity lesions are an important source of infection. These patients are usually sputum smear positive. Coughing produces tiny infectious droplets usually 3000 droplet nuclei, and these can stay in the air for long period of time [17]. The TB bacilli divide every $16-20 \mathrm{~h}$, an extremely slow rate compared with other bacteria, which usually divide in less than an hour.

When the disease is active, $75 \%$ of the cases are pulmonary TB. Symptoms include chest pain, coughing up blood, and a productive cough for more than 3 weeks. Systemic symptoms include fever, chills, night sweats, appetite loss, weight loss, pallor, and fatigue. In the other $25 \%$ of active cases, the infection may spread to other organs known as extrapulmonary TB. The pathogenesis in TB is tissue immune response and formation of granulomas comprising cells of monocyte lineage, multinucleated giant cells, and $\mathrm{T}$ lymphocytes. In the early stage, neutrophils are present, Where as more advanced disease is characterized by caseous necrosis and finally deposition of calcium. The diagnosis of TB was made by blood or sputum culture, X-ray, CT chest, skin test, IGRAs in vitro blood test, and PCR tests. However, in developing world, a rapid and inexpensive diagnostic test would be valuable [18]. The acid-fast (Ziehl-Neelsen) smear is rapid and inexpensive test that can be performed with a minimum of equipment and is very specific for mycobacteria.

A very less number of studies on hematological abnormalitiesin pulmonary TB in India were available. Now, we did a prospective observational study in persons who attended outpatient or admitted in Saveetha Medical College, Thandalam, Kancheepuram district, Tamil Nadu, diagnosed as TB by sputum-positive AFB and associated hematological changes.

Zamen et al. found that men are more commonly affected by PTB than women. Our study showed that PTB was more in male patients than female patients and correlated with the Zamen et al. [19].

The mean $\mathrm{Hb}$ levels in males were $11.13 \mathrm{~g} / \mathrm{dl}$ and in females $9.8 \mathrm{~g} / \mathrm{dl}$. The definition of anemia used in this study $\mathrm{Hb}$ concentration $<11 \mathrm{~g} /$ $\mathrm{dl}$ in males and $<10 \mathrm{~g} / \mathrm{dl}$ in females. The causes of anemia are reduced hemoglobin production, reduced DNA synthesis, reduced stem cell production, bone marrow infiltration, infection, increased red cell destruction, and acute or chronic blood loss. In patients with infection, inflammatory or neoplastic disease having mild-to-moderate anemia persists more than 1-2 months is called anemia of chronic disease. All chronic infections including TB can cause anemia.

Anemia was present in 116 patients (77.3\%), of which males were 88 and females were 28 . The prevalence of anemia was higher in patients whose sputum positivity was $3+(74 \%), 2+(77 \%)$ and $1+(74 \%)$. Based on the $\mathrm{RBC}$ indices, the common type of anemia was normocytic normochromic, 76\% (Tables 2 and 3). In 36 patients, 24\% have microcytic hypochromic anemia and $<1 \%$ patients have macrocytic anemia. In Saudi Arabia, a case-control study was done in PTB patients about hematological changes. In this study, anemia occurred in $60 \%$ of male and $45 \%$ of female patients and showed normocytic normochromic anemia in $80 \%$ of the patients, while $20 \%$ of PTB patients had microcytic hypocromic anemia. Our study was correlated with above study and also agreed with the study done by Al-Omer et al and in India by Yaranal et al. [20,21]. Some studies postulated that the anemia in TB patients was an absence of bone marrow iron, suggesting that iron deficiency is a possible cause of anemia in TB patients. Hypoferremia can be caused by tumour necrosis factor alpha, interleukin (IL-1), and IL-6 which are T helper (TH)-1 cytokines. TNF- $\alpha$ and other cytokines (IL-1) released by activated monocytes suppress the erythropoietin production by independent of the hypoxia-inducible factor pathway-1 leading to anemia [22]. TNF- $\alpha$ and IL-1 enhance iron uptake and ferritin synthesis [23]. In infections, inflammatory, and neoplastic disorders, the erythropoietin is a limited increase and is inappropriately low for the degree of anemia [24].

Depending on the sputum smearing positivity, the leukocyte response was varied. Leukocytosis was present in 68 patients $(45.3 \%)$, of which males were 49 and females were 19. The increased prevalence of leukocytosis present in patients with sputum smear showing $2+$ is $57 \%$, next highest in patients with sputum smear showing $3+$ is $55 \%$, and in patients with $1+$ is $42 \%$. Neutrophilic leukocytosis was observed in 90 patients, of which males were 73 and females were 17 , and the results are similar with Olaniyi et al. [25] who reported neutrophilia associated with acute inflammation and bacterial infection. Eosinophilia was observed in 15 patients, of which males were 12 and females were 3 , this indicates that patients had infection. Some studies reported that changes in relative number of lymphocytes, monocytes, and polymorphonuclear leukocytes had not proved useful either as clinical or prognostic value (Tables 2 and 3) [26].

Table 2: Hematological profile in sputum-positive pulmonary TB of male

\begin{tabular}{ll}
\hline Males & Mean \pm SD \\
\hline Age & $50.7 \pm 13.4$ \\
Hemoglobin & $11.13 \pm 2.4$ \\
TLC & $10713 \pm 3526$ \\
Neutrophil & $76.73 \pm 10.4$ \\
Lymphocytes & $15.3 \pm 7.9$ \\
Eosinophils & $2.8 \pm 3.7$ \\
Monocytes & $4.8 \pm 2.2$ \\
Basophils & $0.3 \pm 0.35$ \\
PCV & $34.6 \pm 6.9$ \\
RBC & $4.14 \pm 0.8$ \\
MCV & $82.5 \pm 10.6$ \\
MCH & $26.9 \pm 3.2$ \\
MCHC & $33 \pm 7.7$ \\
ESR & $57.9 \pm 41.6$ \\
Platelets & $3.4 \pm 1.3$ \\
\hline
\end{tabular}

TB: Tuberculosis

Table 3: Hematological profile in sputum-positive pulmonary TB of females

\begin{tabular}{ll}
\hline Females & Mean \pm SD \\
\hline Age & $37.2 \pm 17.6$ \\
Hemoglobin & $9.8 \pm 2$ \\
TLC & $10647.8 \pm 4303$ \\
Neutrophil & $72.1 \pm 10.6$ \\
Lymphocytes & $17.5 \pm 8.8$ \\
Eosinophil & $1.6 \pm 2.4$ \\
Monocytes & $4 \pm 2.3$ \\
Basophil & $0.23 \pm 0.19$ \\
PCV & $31.4 \pm 6.4$ \\
RBC & $4.03 \pm 0.82$ \\
MCV & $76.8 \pm 10.6$ \\
MCH & $25.2 \pm 11.6$ \\
MCHC & $31 \pm 1.8$ \\
ESR & $72.3 \pm 38.7$ \\
Platelets & $3.34 \pm 1.29$ \\
\hline
\end{tabular}

SD: Standard deviation, TB: Tuberculosis 
Lymphocytopenia was observed in 70 cases. The exact cause for the development of lymphocytopenia has not been diagnosed, but some studies suggested that TNF- $\alpha$ place a role in the pathogenesis of lymphocytopenia [18]. Some studies reported thromobocytosis in patients with military or disseminated TB [27]. A study done by Morris et al. in pulomonary TB showed that more than $50 \%$ of patients have thrombocyosis. In the present study, thrombocytosis was present in 50 patients (33.3\%), of which males were 38 and females were 12, and our study correlated with the findings of Mores et al. and Yaranal et al. Prevalence of thrombocytosis in TB patients with sputum smear showing $1+$ is $29 \%, 2+$ is $31 \%$, and $3+$ is $51 \%$ (Tables 1-3). Thrombocytosis was highest in male patients than females. The stimulus for increased production in TB is not clear [28]. Various inflammatory cells, cytokines, and other mediators are involved in the formation of granulomatous lesions in TB, and IL- 6 has been known to promote platelet production [29]. Since platelets have been proposed as immune cells in recent years, the distinctive morphologic feature of platelets with higher PDW and MPV values in TB may be reflection of an activated platelet form as observed for most other cells of the immune system. Thrombocytopenia was seen in 5 cases, of which 4 in males and 1 in female. Goldenberg suggested that identification of pancytopenia in association with TB may be due to drug toxicity or another underlying process and requires further evaluation [30].

In our study, ESR was elevated in $82 \%$ of patients, of 91 cases, males were 57 and females were 18, and it was an indicator of disease severity and prognostic tool. ESR was elevated higher in male patients than female patients. Bala et al. [31] and the study done by Olaniyi et al. found that increased ESR value in maximum patients [25].

\section{CONCLUSION}

The hematological changes observed in TB patients suggested that the differential diagnosis of TB should be considered in patients with different hematological disorders. The importance of our study was a comparison of hematological changes with bacteriological index (severity of sputum positivity) in PTB patients and till now no one done this study. In our study, the persons with increased bacteriological index showed an increased prevalence of anemia, leukocytosis, neutrophilia, relative lymphopenia, and thrombocytosis and also the incidence was higher in males than female patients. Hence, there was an association between severity of the infection and hematological changes.

Awareness of the clinical, laboratory features, and demographics of TB patients may facilitate early diagnosis. The unexplained presence of any of these hematological abnormalities should raise suspicion of the disease.

As ESR was done routinely along with other basic investigation for the diagnosis of TB, and it was an indicator of disease severity and as a monitoring tool for response to treatment in conditions in which it was raised.

In most of the cases, culture was not done, so we excluded this parameter.

\section{AUTHORS CONTRIBUTION}

All authors have contributed equally.

\section{CONFLICTS OF INTERESTS}

None.

\section{REFERENCES}

1. Sauders E. Robbins Basic pathology. $8^{\text {th }}$ ed. London: Cambridge Press; 2007. p. 516-20

2. Park K. Park's Text Book of Preventive and Social Medicine. $23^{\text {rd }}$ ed. Jabalpur: Banarsidas Bhanot; 2015. p. 176-83.

3. WHO. Weekly Epidemiological Record. $23^{\text {rd }}$ ed. Geneva: WHO; 2004. p. 4.

4. Olive VM, Cezario GA, Cacto RA. Pulmonary tuberculosis: Hematology, serum biochemistry and relationship with the disease condition. J Venom Anim Toxins Incl Trop Dis 2008;14:71-8.

5. Youmans GP, Paterswon PY, Sommers HM. The Biological and Clinical Basis of Infectitious Diseases. $2^{\text {nd }}$ ed. Philadelphia: W. B. Saunders; 1980.

6. Shaji J, Sheikh M. Drug resistance tuberculosis: Recent approach in polymer based nanomedicine. Int J Pharm Pharm Sci 2017;8:1-6.

7. Iseman MD, Bentz RR, Fraser RI, Locks MO, Ostrow JH, Sewell EM. Guidelines for the investigation and management of tuberculosis contacts. American Thoracic Society. Ann Rev Res Dis 1976;114:459.

8. Comstock GW. Tuberculosis in twins: A re-analysis of the prophit survey. Am Rev Respir Dis 1978;117:621-4.

9. Govt. Of India. TB India, RNTCP Status Report, Central TB Division. New Delhi: Ministry of Health and Family Welfare; 2008.

10. Southwick L. Testing Tuberculosis. $4^{\text {th }}$ ed. Philadelphia, PA: Australian Publishing; 2007. p. 1218.

11. Govt. Of India. TB India RNTCP Status Report, Central TB Division. New Delhi: Ministry of Health and Family Welfare; 2010

12. Govt. Of India. Guidlines On programmatic Management of Drug Resistant TB in India. New Delhi: Ministry of Health and Family Welfare; 2012 .

13. WHO. TB/HIV, A Clinical Manual. $2^{\text {nd }}$ ed. Geneva: World Health Organization; 2004.

14. WHO. Policy Frame Work for Implementing New Tuberculosis Diagnostics. Geneva: World Health Organization; 2010.

15. Machado Russo De Moura AC, Court Gonzalez Mosegui GB, Manso De Mello Vianna CI, Cordeiro BC. Cost effectiveness analysis of directly observed therapy for tuberculosis and its expansion in Rio de Janeiro CIty. Int J Pharm Pharm Sci 2017;9:171-5.

16. Global Tuberculosis Control WHO. Geneva. Available from: http:// www.who.int/tb/publications/global report, 2015.

17. Vijayan V, Sagal Das K, editors. Pulmonary Tuberculosis h Suredrasharma Tuberculosis. $1^{\text {st }}$ ed. New Delhi: Jaypee Publisher; 2009. p. 217-27.

18. Philip CH. USA Tuberculosis and othe mycobacterial disease. In: Murray and Nadels Text Book of Respiratory Medicine. $4^{\text {th }}$ ed. Philadelphia, PA: Elsevier; 2005. p. 979-97.

19. Zaman K. Tuberculosis: A global health problem. J Health Popul Nutr 2010;1:111-3.

20. Al-Omar IA, Ashban RM, Shah AH. Hematological abnormalities in Saudis suffering from pulmonary tuberculosis and their response to the treatment. Res J Pharmacol 2009;3:78-85.

21. Yaranal PJ, Umashankar T, Harish SG. Hematological profile in pulmonary tuberculosis. Int J Health Rehabil Sci 2013;2:50-5.

22. Singh KJ, Ahulwalia G, Sharma SK, Saxena R, Chaudary VP, Anant M. Significance of haematological manifestations in patients with tuberculosis. J Asso Physicians Ind 2001;49:788-94

23. Robert T, Mean JR. The anaemia of chronic disorder. Wintrobes Haematol 2005;106:3268-70.

24. Weiss G, Bogdan C, Hentz MW. Pathways for regulation of macrophage Iron metabolism by the anti-inflammatory cytokines IL-4 and IL-13. J Immunol 1997;158:420-5.

25. Olaniyi JA, Aken'Ova YA. Haematological profile of patients with pulmonary tuberculosis in Ibadan, Nigeria. Afr J Med Sci 2003;32:239-42

26. Tanzeela T, Bshir MB, Yaqoob M. Comparative efficacy of different laboratory technique used in diagnosis of tuberculosis in human population. J Med Sci 2001;2:137-44.

27. Maartens G, Willcox PA, Benatar SR. Millary tuberculosis: Rapid diagnosis, hematologic abnormalities and outcome in 109 treated adults. Am J Med 1990;89:291-6

28. Baynes RD, Flax H, Bothwell TH, McDonald TP, Atkinson TP, Chetty N, et al. Reactive thrombocytosis in pulmonary tuberculosis. J Clin Pathol 1987;40:676-9.

29. Kartloglu Z, Cerrahoglu K, Okutan O, Ozturk A, Aydilek R. Parameters of blood coagulation in patients with pulmonary tuberculosis. Internet $\mathrm{J}$ Intern Med 2001;2: 2 .

30. Goldenberg AS. Haematological abnormalities and mycobacterial infection. In: Williams NR, Stuart GM, editors. Tuberculosis. Boston: Little-Brown Company; 1996. p. 645-7.

31. Bala J, Bagdi R, Bedi S, Kumar A. Tuberculosis as a cause of change in haematological parameters in tertiary Care Hospital. Natl J Integr Res Med 2015;6:31-5. 